\title{
CONCEIVE-DESIGN-IMPLEMENT-OPERATE (CDIO) APPROACH FOR AN INNOVATIVE CAPSTONE PROJECT
}

\author{
Jambari, H. ${ }^{1}$, Razali, N.A. ${ }^{2}$ Taman,I. ${ }^{3}$, Noh@Seth,N.H. , \\ Osman, S. ${ }^{5}$, Ahmad, J. ${ }^{6}$, Mohamad Nordin, N. ${ }^{7}$ \& Mohd Rameli , M.R. ${ }^{8}$ \\ 1,2,4,5,6,8 Faculty of Social Sciences and Huminities, Universiti Teknologi Malaysia (UTM), Skudai \\ Malaysia \\ ${ }^{7}$ Faculty of Engineering, Universiti Teknologi Malaysia (UTM), Skudai Malaysia \\ ${ }^{3}$ Politeknik Ibrahim Sultan, Pasir Gudang, Johor, Malaysia
}

Correspondence author email: hanifah-j@utm.my

Received August 15 ${ }^{\text {th }}, 2018$; Accepted November $1^{\text {st }}, 2018$

\begin{abstract}
The development of engineering education plays an important role in promoting a comprehensive national strength due to the scientific innovation results in great changes of industry structure. Therefore, conceive-design-implementoperate (CDIO) approach recognises that the engineering education can be acquired from a variety of institutions and the educators in all parts of this spectrum can learn the practice elsewhere. Thus, the purpose of this study is to identify the students and lecturers' perceptions on the CDIO approaches in a capstone project in two faculties, namely Faculty of Biosciences \& Medical Engineering (FBME) and Faculty of Electrical Engineering (FKE) at Universiti Teknologi Malaysia (UTM). The respondents were five lecturers each from FBME and FKE who were directly involved with the capstone project and 28 and 30 third-year students from FBME and FKE respectively. The 5-point Likert scale questionnaires used had been validated by an expert panel with adequate reliability. The data analysis results indicate that the students and lecturers have positive perceptions of the CDIO approaches when used in the capstone project. Thus, the approach can be successfully implemented in an undergraduate engineering programme to enhance their technical skill particularly to produce creative and innovative project which is in line with current technology.
\end{abstract}

Keywords: CDIO approach; innovation education; capstone project; engineering education

DOI: https://10.30880/jtet.2018.10.02.008 


\section{INTRODUCTION}

There are many factors that drive the curriculum change in higher engineering education such as to establish alternatives in traditional programme consists of disciplinary theoretical courses (Sheppard et al., 2009). The background in engineering education is a necessity to increase the quality and to improve the processes and results of education, such as to increase the attractiveness to prospective students, to lower the attrition, and to improve the preparation for professional practice which contributes to sustainable development, innovation, and job creation (Naziha \& Hanifah, 2017).

Currently, the competitions between countries are not only for talents but also for the reserved of talents. Engineering science that supports all industries are able to maintain and promote the economic stability and development. Besides, the development of engineering education plays an important role in promoting comprehensive national strength as the scientific innovation results in great changes of industrial structure. Engineering education must anticipate and adapt to this variation to transform the engineer's role from working with lower technological engineering to a knowledge-based service economy (Naziha \& Hanifah, 2017).

There are a variety of ways for an institution to adapt to ongoing changes (Graham, 2012). There are projects which are designed, carried out, and reported purely internally, while others are inspired by more established approaches, sharing, and discussion of the problem analyses, methodologies, and results in wider communities. According to Abata, Andersen, \& Krause, (2013), the educational process in the European Project Semester (EPS) programme is best described as experiential learning, such as students acquire information through the study of a subject as opposed to textbook exposure.

The adoption of CDIO in engineering educators is important to establishment in engineering education and necessitates a new way of conceptualizing teaching and learning. Schneckenberg (2009) was argued that the faculty faced tensions within the various levels of the embedded systems and contexts in which they found themselves as they considered the adoption of innovations. From the activity theory of perspective where the introduction of a new pedagogical implementation in the classroom system an innovation brings with it a set of tensions (Engeström, 2001). Tensions will arise within each level of the system where each may have its own goals, rules, values, processes and procedures that facilitate the interactions within and between systems. The teaching beliefs and intentions of educator will be impacted by the facilitate parameters of a system.

The purpose of this study is to identify the students' and lecturers' perceptions of the importance of the CDIO approaches in capstone project from the Department of Biotechnology and Medical Engineering under the Faculty of Biosciences and Medical Engineering (FBME), and from the Department of Control and Mechatronic Engineering under the Faculty of Electrical Engineering (FKE) at Universiti Teknologi Malaysia (UTM). From this finding, the perception of CDIO approach is important to implement in the project capstone to support the engineering faculty in producing graduates with marketable value in line with current industry demands.

\section{PROBLEM BACKGROUND}

Nowadays, educators in engineering have to create a learning environment that not only address the need for teaching technical skills but also for the development of entrepreneurial skills (Shuman, BesterfieldSacre, \& McGourty, 2005). Engineering educators must also take into account the attributes that 
graduates should possess, starting from the first year of their engineering studies (Sheppard, Macatangay, Colby, \& Sullivan, 2009).

The vast technical knowledge and skills in engineering curriculum are not the only skills required among engineering graduates (Trevelyan, 2008). The industry has been demanding multi-skilled engineer go well-beyond the technical mastery (Duderstadt, 2008) which includes self-directedness, teamwork, and communication. Employability skills and entrepreneurship are accompanied by generic skills can be achieved if holistic education with basic amenities such as teaching equipment must be up to date with the current industry and technology development (Hanifah et. al.,2018)

The industry began to find that graduating engineering students, when it is technically adept, lacked many skills and required in real world engineering situations (Wankat, 1993). This is because they found that the traditional teaching methods that often failed to achieve the goals which set out by industry. The CDIO initiative has recognized a big variance between the skills required by industry and that for the graduating students possesses and contributes this to lack of balance between engineering practice and also engineering science (Crawle, Malmqvist, Östlund, \& Brodeur, 2007).

Therefore, the CDIO approach, which stands for conceive-design-implement-operate approach, has been recognized important in engineering education and can be acquired over a long period in a variety of institutions. Educators in all parts of this spectrum can learn the practice everywhere. The adoption of the CDIO approach among engineering educators is an important establishment in engineering education and necessitates a new way of conceptualizing teaching and learning. With pedagogical innovations like CDIO, comfortable routines related to the structure and flows of classroom activity are disrupted for both educators and students. In addition to having to manage changes within their classroom processes and routines, engineering educators must also interact and operate within the larger system in which their classroom is embedded, the university. The structure and culture of the university system may facilitate or hinder the teaching intentions and goals of educators, as this larger system can impose its own set of tensions.

Due to the importance of CDIO approach in a capstone project in UTM, this paper focused to identify on the perception of CDIO educational approaches in two faculties in UTM including students and lecturers. The finding can be used as a guideline for engineering faculty in UTM to enhance the method of teaching and learning particularly in capstone project that must in line with current technology and industry demands. Besides that, from four departments in FKE, there is only one department was used the CDIO approaches actively in their study which is Department of Control and Mechatronic Engineering (CMED) and for the FBME, there are also only one out of three departments used the CDIO approach in their study which is Department of Biotechnology and Medical Engineering.

\subsection{Framework for CDIO}

UTM has started implementing the Conceive-Design-Implement-Operate framework when Temasek which sponsored the Singapore Polytechnic (SP) - began sharing their expertise in CDIO throughout Asia. As part of the sharing programme, SP has conducted a series of train the trainer courses for UTM lecturers. Since then, UTM has started implementing the CDIO approach with a total of 15 CDIO Master Trainers in UTM. 
The implementation of the New Academia model in UTM focuses on teaching and learning innovation, which encourages the high impact changes and transforms from conventional thinking to entrepreneurial thinking among the academician, as well as graduates. The CDIO approach is a part of the New Academia Learning Innovation Model as shown in Figure 1.

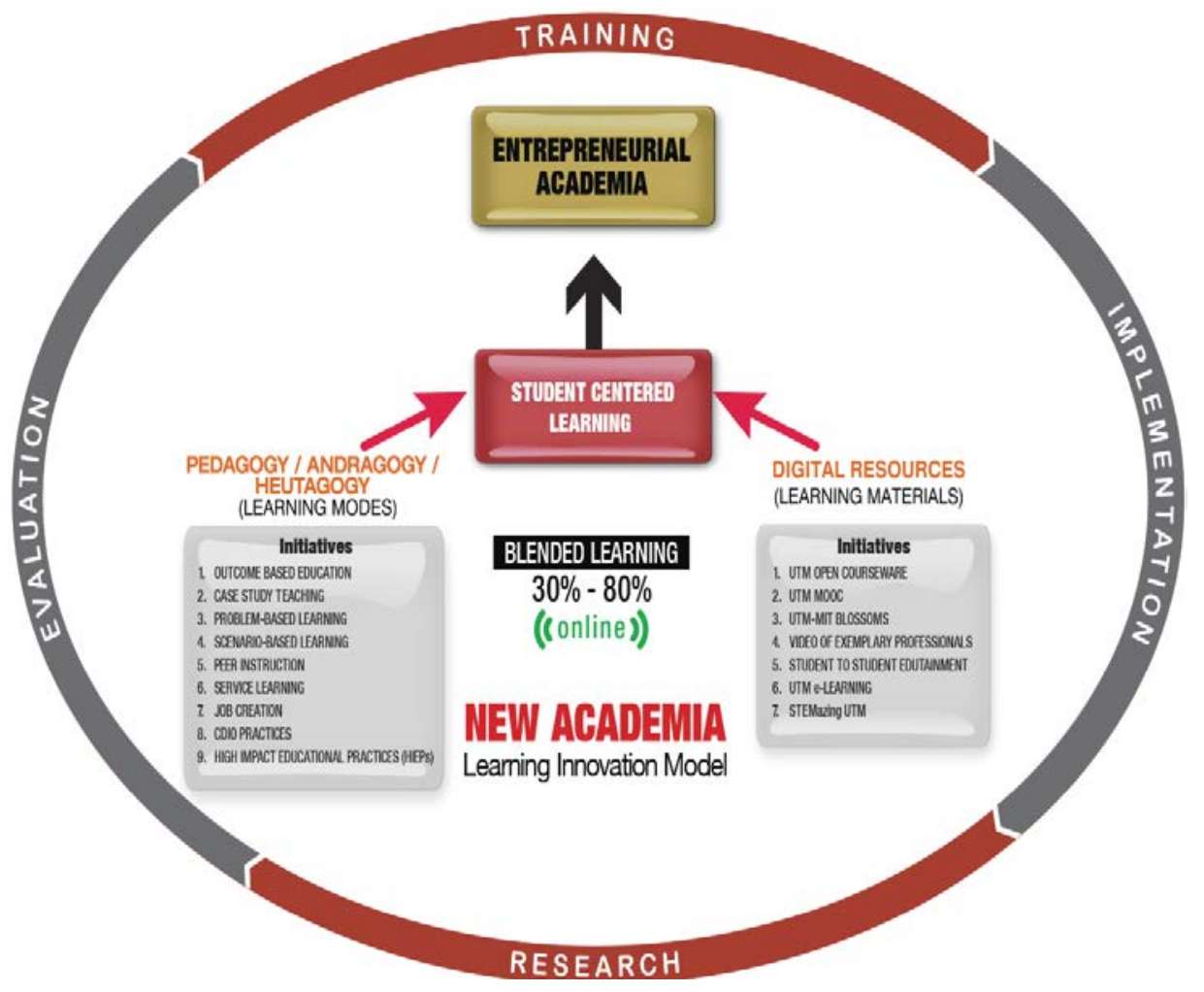

Figure 1: Model of New Academia Learning Innovation (NALI,2016)

The Singapore Polytechnic is the first educational institution in Asia as a CDIO collaborator in 2004 and has implemented the CDIO framework in its engineering courses successfully in 5 faculty schools and 15 diploma programme since 2007. Central to CDIO is an engineering education framework developed by Massachusetts Institute of Technology (MIT) and adopted by more than 50 universities all over the world.

\section{$2.2 \quad$ Research objectives}

The aim of this study was to investigate the perceptions of FBME and FKE students and lecturers' towards the CDIO approaches used in their innovative capstone project. Furthermore the study also aims to identify the importance of CDIO approach in FKE and FBME capstone project.

\section{METHODOLOGY}

For the purpose of this study, a non-experimental approach was used to identify the perceptions of students and lecturers on the use of CDIO approach for an innovative capstone project. Quantitative data 
were gathered using a 5-point Likert scale questionnaire. Questionnaires were distributed to students manually while the online survey by using Google form was used to distribute the questionnaire to lecturers.

Lecturer participants were five lecturers who used the CDIO approach on the third year students. Students participants were fifty eight third year students, 28 of them were from FBME and the remaining 30 were students from FKE. These students had the experience of conducting the innovation capstone project using the CDIO approaches.

Descriptive statistics analysis methods were used to analyse these data with the aid of SPSS to calculate the mean, median, percentage and standard deviation. Reliability analysis was also conducted using the Cronbach's Alpha method. Questionnaire reliability was estimated as Alpha equals .865 indicating that the instrument has a high degree of reliability.

\section{DATA ANALYSIS AND RESULTS}

This section presents the results of the data analysis starting with the analysis of students' survey data and followed by lecturers' data.

\subsection{Students Survey}

The 5-point Likert scale was used to survey students' perception in this study. Interestingly FBME had higher percentage of female students compared to FKE; $28.57 \%$ males and $71.43 \%$ females came from FBME $(n=28)$ and $46.67 \%$ males and $53.33 \%$ females came from FKE $(n=30)$. In both groups, females were dominant.

The mean (M), median, and standard deviation (SD) were calculated for each item in the questionnaire to determine items that students are in agreement and disagreement most. As a reminder, these data were from students of two faculties, namely the Faculty of Biosciences and Medical Engineering (FBME) and the Faculty of Electrical Engineering (FKE).

\subsubsection{Items for the students perception of the CDIO approach}

The mean, median, and standard deviations on all items on students' perception of the CDIO approach in a capstone project are shown in Table 1 . The means and medians were roughly similar indicating that the data distribution was approximately normal. The standard deviations were mostly less than 1 indicating that most data are closer to the mean value. FBME students have greater means on three out of four perception items compared to FKE students with the largest difference on Item 1; $M=4.46$ for FBME, and $\mathrm{M}=4$ for FKE . This is because most students from FBME "strongly agree" to the statement in Item 1 and most students from FKE "agree" to the statement in Item 1. For Item 2 and Item 4, both faculties "agree" with the statement. For Item 3, most students from FKE "agree" with the statement with the mean value of 3.40. On the contrary, the result shows differently for the students from FBME where most students' recorded the "neutral" result with the mean value of 3.32 . 
Table 1: Descriptive statistics for items on students' perception of the CDIO approach

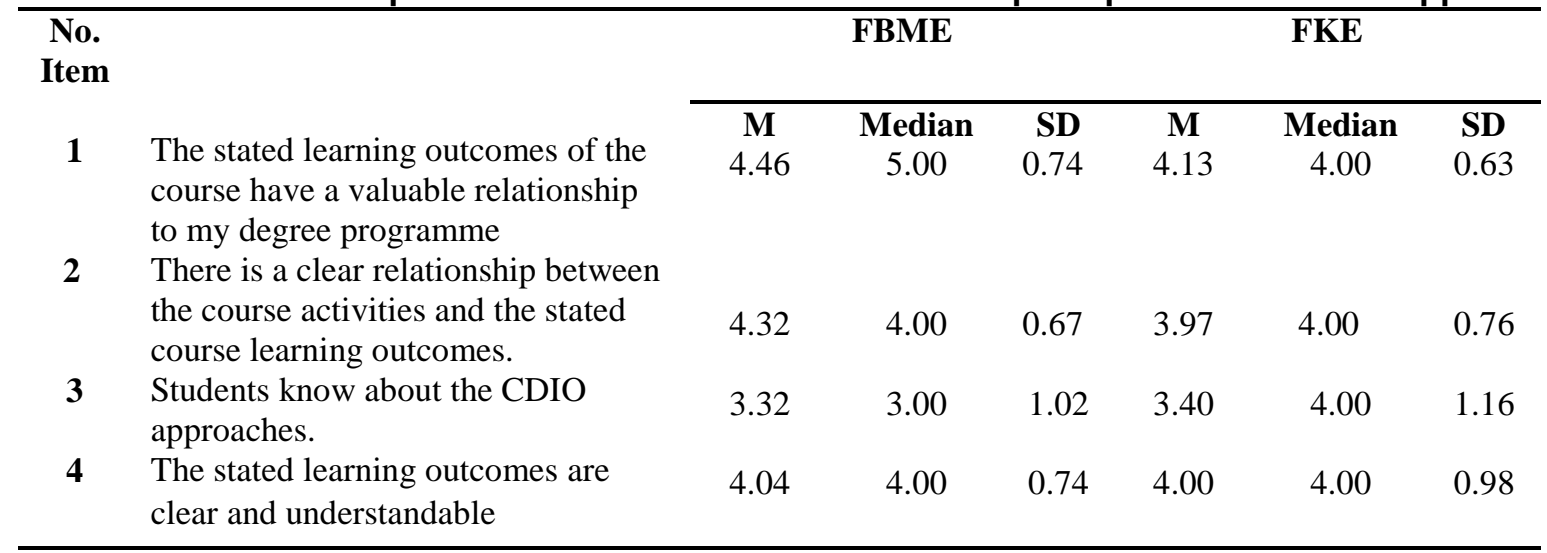

\subsubsection{Importance of CDIO in Capstone Project}

Table 2 lists the Items used to assess the importance of CDIO in a Capstone Project.

Table 2: M, median and SD for items on the importance of CDIO in Capstone Project

\begin{tabular}{|c|c|c|c|c|c|c|c|}
\hline \multirow{2}{*}{$\begin{array}{l}\text { No. } \\
\text { Item }\end{array}$} & & \multicolumn{3}{|c|}{ FBME } & \multicolumn{3}{|c|}{ FKE } \\
\hline & & $\mathbf{M}$ & Median & SD & $\mathbf{M}$ & Median & SD \\
\hline 5 & $\begin{array}{l}\text { CDIO approaches of learning would } \\
\text { be a waste of time. }\end{array}$ & 2.00 & 2.00 & 1.19 & 3.37 & 3.50 & 1.07 \\
\hline 6 & $\begin{array}{l}\text { CDIO requires more time to execute } \\
\text { the lesson. }\end{array}$ & 3.71 & 4.00 & 1.08 & 3.73 & 4.00 & 0.64 \\
\hline 7 & $\begin{array}{l}\text { CDIO strengthens the capabilities } \\
\text { and skills of the students. }\end{array}$ & 4.21 & 4.00 & 1.03 & 3.90 & 4.00 & 0.80 \\
\hline 8 & $\begin{array}{l}\text { CDIO approach, teacher must act as } \\
\text { facilitator and not a lecturer. }\end{array}$ & 4.36 & 4.50 & 0.83 & 4.13 & 4.00 & 0.78 \\
\hline 9 & $\begin{array}{l}\text { CDIO motivate students to be } \\
\text { independent. }\end{array}$ & 4.39 & 4.00 & 0.57 & 4.17 & 4.00 & 0.70 \\
\hline 10 & $\begin{array}{l}\text { CDIO help students measure their } \\
\text { own performance. }\end{array}$ & 4.32 & 4.00 & 0.72 & 4.13 & 4.00 & 0.63 \\
\hline 11 & $\begin{array}{l}\text { CDIO promote the responsiveness of } \\
\text { the faculties' activities towards the } \\
\text { enhancement of students' academic } \\
\text { performance. }\end{array}$ & 4.21 & 4.00 & 0.83 & 4.00 & 4.00 & 0.69 \\
\hline 12 & $\begin{array}{l}\text { CDIO develop the study habits of the } \\
\text { students. }\end{array}$ & 3.75 & 4.00 & 0.93 & 4.07 & 4.00 & 0.83 \\
\hline 13 & $\begin{array}{l}\text { CDIO challenge students to become } \\
\text { more competitive. }\end{array}$ & 4.39 & 4.50 & 0.74 & 5.13 & 4.00 & 7.39 \\
\hline 14 & $\begin{array}{l}\text { CDIO practice collaboration rather } \\
\text { than competition }\end{array}$ & 4.07 & 4.00 & 0.94 & 3.97 & 4.00 & 0.89 \\
\hline 15 & $\begin{array}{l}\text { CDIO creates a mindset towards a } \\
\text { clear direction of learning }\end{array}$ & 4.36 & 4.00 & 0.68 & 3.87 & 4.00 & 0.82 \\
\hline
\end{tabular}

Vol. 10, No. 2| December 2018| ISSN 2229-8932 Journal of Technical Education and Training (JTET) |87 
The mean value for Item 5 until 16 where Item 6 until Item 15 for both faculties recorded that the students mostly "agree" with the statement. Besides, Item 5 recorded the mean value of 2.00 for FBME students, which mean most of the students "disagree" with the statement. However, the result shows the mean value of 3.37 for FKE students reflecting that most of the students chose "neutral" for the statement.

\subsection{Lecturers Survey}

The mean, median, and standard deviation were calculated to find which Item the lecturers agree and not agree with using SPSS 18.0. There are two categories of lecturers, namely from the Faculty of Biosciences and Medical Engineering (FBME) and the Faculty of Electrical Engineering (FKE)

\subsubsection{Lecturers' Perception of CDIO Approach}

Lecturers’ perception of CDIO approach in capstone project is illustrated in Table 3.

Table 3: Descriptive statistics on items for lecturers' perception of CDIO approach

\begin{tabular}{|c|c|c|c|c|c|c|c|}
\hline \multirow{2}{*}{$\begin{array}{l}\text { No. } \\
\text { Item }\end{array}$} & & \multicolumn{3}{|c|}{ FBME } & \multicolumn{3}{|c|}{ FKE } \\
\hline & & $\bar{M}$ & Median & SD. & $\mathbf{M}$ & Median & SD \\
\hline 1 & $\begin{array}{l}\text { CDIO approach is suitable for the } \\
\text { FKE/FBME in capstone project }\end{array}$ & 5.00 & 5.00 & 0.00 & 4.80 & 5.00 & 0.45 \\
\hline 2 & $\begin{array}{l}\text { To educate students who are able to } \\
\text { understand the importance and } \\
\text { strategic impact of research and } \\
\text { technological development on } \\
\text { society. }\end{array}$ & 4.40 & 4.00 & 0.55 & 4.60 & 5.00 & 0.55 \\
\hline 3 & $\begin{array}{l}\text { CDIO implementation has led to } \\
\text { increase operating costs. }\end{array}$ & 3.60 & 4.00 & 1.52 & 3.80 & 4.00 & 0.84 \\
\hline 4 & $\begin{array}{l}\text { Students improve the quality of } \\
\text { understanding the problem in their } \\
\text { project. }\end{array}$ & 4.40 & 4.00 & 0.55 & 4.60 & 5.00 & 0.55 \\
\hline 5 & $\begin{array}{l}\text { To educate students who are able to } \\
\text { lead in the creation and operation of } \\
\text { new products, processes, and } \\
\text { systems }\end{array}$ & 4.60 & 5.00 & 0.55 & 4.80 & 5.00 & 0.45 \\
\hline
\end{tabular}

The mean values for Item 1 until Item 5 . Item 1 and Item 5 show that lecturer from both faculties "strongly agree" with the statements. Item 3 also shows the same trend for the lecturers in both faculties where most of the lecturers "agree" with the statement. FBME lecturers mostly "agree" with the statement in Item 2, while lecturers from FKE "strongly agree" with the statement. The same trend was observed to Item 4 where most lecturers from FBME "agree" with the statement, however, most FKE lecturer "strongly agree" with the statement.

\subsubsection{Lecturer's perceptions on the importance of CDIO in Capstone Project}

The mean, median and standard deviation of items on the importance of CDIO in capstone project is illustrated in Table 4. 
Table 4: Descriptive statistics on Items for the importance of CDIO in a Capstone Project

\begin{tabular}{|c|c|c|c|c|c|c|c|}
\hline \multirow{2}{*}{$\begin{array}{l}\text { No. } \\
\text { Item }\end{array}$} & & \multicolumn{3}{|c|}{ FBME } & \multicolumn{3}{|c|}{ FKE } \\
\hline & & $\mathbf{M}$ & Median & SD & $\overline{\mathbf{M}}$ & Median & SD \\
\hline 6 & CDIO important in capstone project & 4.60 & 5.00 & 0.55 & 4.60 & 5.00 & 0.55 \\
\hline 7 & $\begin{array}{l}\text { CDIO stimulates students' interest } \\
\text { and strengthens their motivation in } \\
\text { the field of engineering }\end{array}$ & 4.60 & 5.00 & 0.55 & 4.60 & 5.00 & 0.55 \\
\hline 8 & $\begin{array}{l}\text { The ability for students to apply } \\
\text { engineering science, in design- } \\
\text { implement experiences integrated } \\
\text { into the curriculum. }\end{array}$ & 4.20 & 4.00 & 0.45 & 4.60 & 5.00 & 0.55 \\
\hline 9 & $\begin{array}{l}\text { May helps students to generate their } \\
\text { ideas for undergraduate research } \\
\text { projects and internships. }\end{array}$ & 4.80 & 5.00 & 0.45 & 4.80 & 5.00 & 0.45 \\
\hline
\end{tabular}

The mean values for Item 6 until Item 9. Item 6, 7, and 9 from both faculties recorded the same result where most lecturers "strongly agree" with the statements. For FBME, the mean value for both Item 6 and Item 7 were similar which are 4.60, while Item 8 and 9 recorded the mean value of 4.20 and 4.8, respectively. For FKE, the mean value for Item 6, 7 and 8 are same, which is 4.6, while Item 9 recorded the mean value of 4.80 . Item 8 shows that most lecturers "agree" with the statement, contradict with FKE lecturers where most of them "strongly agree" with the statement.

\section{DISCUSSION}

This studies was investigated the FBME and FKE students and lecturers' perceptions on the CDIO approaches in their innovative capstone project and also to identify the importance of CDIO in FKE and FBME capstone project where Item 1 until Item 4 from questionnaire shows the mean value for student's perception of the CDIO approach. There are four Items related to the perception of the CDIO approach. Most students from FBME strongly agree with that statement in Item 1, "The stated learning outcomes of the course have a valuable relationship to my degree programme". Whereas most students from FBME agree with the statements "There is a clear relationship between the course activities and the stated coursed learning outcomes" and "The stated learning outcomes are clear and understandable" in Item 2 and Item 4, respectively. According to Anderson, \& Krathwohl (2001), the learning outcome is a direct statement which describes the essence of enduring the disciplinary knowledge, the abilities that the students should possess, and the depth of learning which is expected upon completion of a program or course.

However, the FBME students chose natural for Item 3 which is "Students know about the CDIO approaches” which means that the students are still confused about the CDIO approach. The students need more information regarding the use of CDIO approaches to enhance the knowledge gained through the activities conducted during capstone project. In contrast, most of the FKE students agree with Item 1 until Item 4. It can be concluded that most FKE students understand the concept of the CDIO approaches and their CDIO program follows the UTM NALI Standard 2 learning outcomes accordingly. The curriculum section in UTM NALI includes the methods to specify learning outcomes and design curriculum, with an emphasis on students' introduction of engineering. 
Item 5 until Item 15 shows mean value regarding the importance of the CDIO approach in capstone project between FBME and FKE students. Most of the students from the FBME disagree with the negative statement for Item 5, "CDIO approaches of learning would be a waste of time", while most of the students from the FKE chose natural for the same item indicating that they may not know much about this statement. Most of the students from both faculties agree with these two statements which are, "CDIO approach, the teacher must act as a facilitator and not a lecturer" and "CDIO challenge students to become more competitive", both for Item 8 and Item 13, respectively. In these case, the students from both faculties know that the lecturers only act as their facilitator while applying the CDIO approach in a capstone project. This findings are supported accordingly by Edstrom (2012), where the fundamental principle of the CDIO approach is that the role of facilitators, which are the lecturers, is to guide the students, who are the owner of the learning process, by presenting several ideas, method, and tools for the students to choose from.

For Item 1 until Item 5 shows mean value regarding the lecturers' perception of the CDIO approach between the FBME and FKE lecturers. Item 1 and Item 5 show that most of the lecturers from both faculties strongly agree with the statements "CDIO approach is suitable for the FKE/FBME in capstone project" and "To educate students who are able to lead in the creation and operation of new products, processes, and systems". It shows that lecturers from both faculties support the CDIO approach implementation in a capstone project. According to Alorda, Carmona, Pons (2016), the CDIO method is suitable for engineering course as it focuses on their definition of technical studies. Most lecturers in the FKE agree with Item 3 with the statement "CDIO implementation has led to the increase of operating costs". This is because the lecturers from both faculties know that the implementation of the CDIO approach will increase the operating cost especially from the students where most students need to pay for their own project. Hence, both faculties had followed the Standard 5 NALI which is design-implement experiences (NALI, 2016).

Item 6 until Item 9 shows mean value regarding the importance of the CDIO approach in capstone project among the FBME and FKE lecturers. The result shows that the lecturers in FKE strongly agree with the statements of Item 6 until Item 9. On the other hand, FBME lecturers strongly agree with Item 6, 7, and 9. However, FBME lecturers only agree with the statement for Item 8, "Ability for students to apply engineering science, in design-implement experiences integrated into the curriculum" This statement is to ensure the curriculum materials met the condition of an aligned curriculum and consistent with the relevant CDIO standards, where a close collaborative approach between the faculty and the Educational Development staff is adopted (Crawley et., al. 2007). Overall, the lecturers for both faculties strongly agree with the second research question. UTM NALI Standard 7 focuses on the integrated learning experiences, where both faculties had followed the guideline accordingly (NALI, 2016).

\section{CONCLUSION}

As a conclusion, the undergraduate engineering courses nowadays are facing with the growing tension between two needs, the ever-increasing body of disciplinary knowledge, where all students must command, and secondly, the students must possess a wide variety of personal, interpersonal and system building knowledge and skills. From the analysis result gathered from the students and lecturers surveys on the CDIO approach in a capstone project, it can be seen that students and lecturers perceive the approach in a positive light and feel that the approach is important to implement in engineering education. Thus, with positive perception and acceptance, the CDIO approach is more likely to be successfully implemented when correctly executed in an undergraduate engineering course. The curriculum however, 
needs to be revised continuously in line with current technology advancement while the assessment on the capstone project must follow the NALI standard which includes appropriate rubric. Well-implemented on the CDIO approach will result the engineering students with high motivation and technical skills in doing their capstone project. As results, the engineering students with be creative, innovative and possess critical thinking in tandem with current technological developments and in line with industry needs.

\section{Acknowledgement}

The authors would like to thank Ministry of Higher Education Malaysia for the Fundamental Research Grant Scheme (FRGS) of this project with Vote number 4F922.

\section{References}

Abata, D.L., Andersen, A. \& Krause, W.B. (2013). Transatlantic Interaction with European Project Semester. Proceedings of the $120^{\text {th }}$ ASEE Annual Conference \& Exposition, Atlanta, USA, American Society for Engineering Education.

Anderson, L. W., \& Krathwohl, D. R. (2001). A taxonomy for learning, teaching, and assessing: A revision of Bloom's taxonomy of educational objectives. New York: Longman.

Alorda Bartomeu, Carmona Cristian, Pons Pedro (2016). Introduction of a CDIO based learning in an automatic electronic engineering degree. International Journal on Advances in Education Research. Vol. 3 No 3: 1-16.

Borrego, M., Froyd, J.E., \& Hall, T.S. (2010). Diffusion of engineering education innovations: A survey of awareness and adoption rates in U.S. engineering departments. Journal of Engineering Education, 99 (3), 185207.

Crawley, E. F., Malmqvist, J., Östlund, S., \& Brodeur, D. R. (2007). Rethinking engineering education: The CDIO approach. New York, NY: Springer.

Duderstadt, J. J. (2008). Engineering for a changing world: A roadmap to the future of engineering practice, research, and education. Ann Arbor, MI: University of Michigan.

Edström, K., \& Kolmos, A. (2012). Comparing two approaches for engineering education development: PBL and CDIO. In Proceedings of the 8th International CDIO Conference.

Engeström, Y. (2001). Expansive learning at work: Toward an activity theoretical reconceptualization. Journal of Education and Work, 14 (1), 133-156.

Hanifah Jambari, Ishak Taman, NurHusnaAbd Wahid, Jamilah Ahmad, Sharifah Osman, Ahmad Nabil Nasir,\& NornaziraSuhairom (2018). Consciousness of Engineering Lecturers in Polytechnics Malaysia for Developing Educational Trainer Research Centre. Journal of Advanced Research in Dynamical and Control Systems, issue (9), 1330-1336.

NALI (2016). A Guide to New Academia Learning Innovation. UTMLead Johor Bahru.

Naziha A. Azli, Hanifah Jambari (2017). Quality of Engineering Graduates of a Malaysian Public University. $7^{\text {th }}$ World Engineering Education Forum. Kuala Lumpur Malaysia.

R. Graham (2012). The Royal Academy of Engineering, "Achieving excellence in engineering education: the ingredients of successful change”, The Royal Academy of Engineering.

Schneckenberg, D. (2009). Understanding the real barriers to technology-enhanced innovation in higher education. Educational Research, 51(4), 411-424.

Sheppard, S., K. Macatangay, A. Colby, \& W. M. Sullivan (2009). Educating Engineers: Designing for the Future of the Field. San Francisco, CA: Jossey-Bass

Shuman, L. J., Besterfield-Sacre, M., \& McGourty, J. (2005). The ABET "professional skills" - can they be taught? Can they be assessed? Journal of Engineering Education, 94(1), 41-5

Trevelyan, J. (2008). Real engineering is not what you learned at school.......or is it? Paper presented at the Research in Engineering Education Symposium (REES), Davos, Switzerland.

Wankat, P.a.O. (1993). Teaching Engineering. London: Mcgraw Hill. 